\title{
ANALISIS KELAYAKAN USAHA PENANGKARAN BENIH KELAPA DI KABUPATEN PANGANDARAN
}

\author{
DIDIN CHAERUDIN*, MUHAMAD NURDIN YUSUF,AGUS YUNIAWAN ISYANTO \\ Fakultas Pertanian Universitas Galuh \\ Email: didinenjoy2@gmail.com
}

\begin{abstract}
ABSTRAK
Kebutuhan benih kelapa unggul merupakan kebutuhan yang sangat mendasar bagi petani khususnya di Kecamatan Parigi, namun kegiatan penangkaran benih di Kecamatan Parigi masih jarang dilakukan oleh para petani karena mereka lebih memilih berusahatani kelapa butiran/kopra. Penelitian ini bertujuan untuk mengetahui: (1) Besarnya biaya, penerimaan dan pendapatan usaha penangkaran benih kelapa, dan (2) Besarnya R/C usaha penangkaran benih kelapa. Penelitian dilaksanakan dengan menggunakan metode survai. Bapak Hendi dipilih secara sensus karena merupakan satu-satunya pengusaha penangkar benih kelapa di Kabupaten Pangandaran. Hasil penelitian menunjukan bahwa: (1) Besarnya biaya Rp 112.519.060, penerimaan Rp 200.000.000, dan pendapatan Rp 87.480.940, dan (2) Besarnya R/C 1,78 yang menunjukkan bahwa dari setiap Rp 1 biaya yang dikeluarkan akan diperoleh penerimaan sebesar $\mathrm{Rp} 1,78$ rupiah dan pendapatan $\mathrm{Rp} 0,78$.
\end{abstract}

Kata kunci: Biaya, penerimaan, pendapatan, $\mathrm{R} / \mathrm{C}$, penangkaran benih kelapa

\section{ABSTRACT}

The need for feature coconut seeds is a very basic requirement for farmers, especially in the District of Parigi, but breeding activities in the District of Parigi are still rarely carried out by farmers because they prefer to cultivate coconut/copra. This study aims to determine: (1) The amount of cost, revenue and income of coconut seed breeding business, and (2) The amount of $R / C$ of coconut seed breeding business. The study was conducted using the survey method. Mr. Hendi was chosen census because he is the only coconut seed breeder in Pangandaran Regency. The results showed that: (1) The amount of the cost of $R p$ 112,519,060, the revenue of $R p$ 200,000,000, and the income of Rp. Received an income of $R p 1.78$ and income of $R p 0.78$.

Keywords: Cost, revenue, income, coconut seed breeding

\section{PENDAHULUAN}

Pembangunan di Indonesia yang merupakan negara agraris, menjadikan sektor pertanian sangat penting bagi perekonomian nasional dan sebagian besar penduduk Indonesia hidup di perdesaan sebagai petani. Sektor pertanian memberikan jasa yang cukup besar terhadap perekonomian Indonesia dan sebagian besar ekspor Indonesia berasal dari sektor pertanian, sehingga sektor pertanian berperan penting dalam penyerapan tenaga kerja serta penyediaan kebutuhan pangan dan sandang bagi penduduk (Yurianto, 2008).

Salah satu komoditas pertanian yang memberikan kontribusi yang cukup besar terhadap perekonomian Indonesia adalah kelapa. Tanaman kelapa adalah salah satu jenis tanaman perkebunan yang banyak ditanam oleh masyarakat perdesaan mengingat tanaman kelapa memiliki peran 
yang cukup besar bagi kehidupan masyarakat terutama sebagai sumber mata pencaharian. Tanaman kelapa masih merupakan tanaman perkebunan di Indonesia yang lebih luas dibandingkan dengan tanaman kelapa sawit. Tanaman ini diusahakan melalui perkebunan rakyat, perkebunan swasta maupun perkebunan pemerintah. Luas areal kelapa ini terdiri atas kelapa jenis varietas dalam dan varietas hibrida, dengan pemeliharaan yang mendalam dapat mencapai penghasilan masing-masing 2,5 ton kopra/ha/thn dan 4 ton kopra/ha/thn (Allorerung dan Mahmud, 2002).

Tanaman kelapa dapat digunakan untuk keperluan pangan atau non pangan. Setiap dari bagian tanaman kelapa bisa berperan penting untuk dimanfaatkan manusia, sehingga pohon kelapa dianggap sebagai tanaman serbaguna dan dijuluki sebagai The Tree of Life (pohon kehidupan), karenanya tanaman kelapa mempunyai nilai ekonomi tinggi (Jumiati, dkk, 2013).

Tanaman kelapa di Kecamatan Parigi tersebar di 10 desa dengan total luas tanam 5.946,22 hektar, luas tanaman menghasilkan 2.819,10 hektar, produksi 578,88 ton, dan produktivitasnya 0,20 ton per hektar.
Kebutuhan benih kelapa unggul merupakan kebutuhan yang sangat mendasar bagi petani, khususnya di Kecamatan Parigi. Namun kegiatan penangkaran benih di Kecamatan Parigi masih jarang dilakukan oleh para petani karena mereka lebih memilih usahatani kelapa butiran/kopra. Hal ini mengakibatkan pasokan benih kelapa lokal bersertifikat pun terus berkurang. Upaya yang dilakukan untuk menanggulangi kekurangan benih kelapa ini yaitu dengan adanya bantuan dari pemerintah seperti program Bantuan Langsung Benih Unggul (BLBU) dan Sekolah Lapang Pengelolaan Tanaman Terpadu (SL-PTT).

Penangkaran benih kelapa unggul sangat diperlukan guna mendukung ketersedian benih varietas unggul dan meringankan beban pemerintah. Penangkaran benih tujuannya untuk memenuhi keperluan benih di suatu daerah dengan produksi benih bermutu terutama di Desa Selasari Kecamatan Parigi Kabupaten Pangandaran. Penangkaran benih di petani merupakan bentuk kemandirian dan keswadayaan petani.

Penelitian ini dilaksanakan dengan tujuan untuk mengetahui: (1) Biaya, penerimaan, pendapatan usaha penangkaran benih kelapa, dan (2) R/C 
pada usaha penangkaran benih kelapa di Kabupaten Pangandaran.

\section{METODE PENELITIAN}

Penelitian dilaksanakan dengan menggunakan metode survai di Desa Selasari Kecamatan Parigi Kabupaten Pangandaran. Menurut Arikunto (2006), metode survai adalah metode penelitian yang dilakukan untuk mengadakan pengukuran-pengukuran dan pemeriksaan terhadap gejala empiris yang berlangsung lokasi penelitian, umumnya dilakukan terhadap sampel yang dihadapi sebagai responden dan bukan seluruh populasi sasaran.

Data yang dikumpulkan meliputi data primer dan data sekunder. Pengumpulan data primer dilakukan dengan cara wawancara terhadap responden dengan menggunakan daftar petanyaan (kuesioner) yang telah disiapkan. Pengumpulan data sekunder dilakukan melalui studi kepustakaan dan mengunjungi dinas atau instansi terkait.

Bapak Hendi diambil sebagai sampel penelitian dengan menggunakan sensus karena merupakan satu-satunya penangkar benih kelapa yang ada di Kabupaten Pangandaran.

Biaya total usaha penangkaran benih kelapa dihitung dengan menggunakan persamaan menurut Soekartawi (2002) sebagai berikut:

$\mathrm{TC}=\mathrm{TFC}+\mathrm{TVC}$

Dimana:

$\mathrm{TC}=$ Total Cost

TFC = Total Fixed Cost

$\mathrm{TVC}=$ Total Variable Cost

Penerimaan dihitung dengan menggunakan rumus menurut Suratiyah (2006) sebagai berikut:

$\mathbf{R}=\mathbf{P y} \cdot \mathbf{Y}$

Dimana:

$\mathrm{R}=$ Revenue (Penerimaan)

Py $=$ Price (Harga Produksi)

$\mathrm{Y}=$ Yield (Jumlah Produksi)

Pendapatan dihitung dengan menggunakan persamaan menurut Suratiyah (2006) sebagai berikut:

$$
\boldsymbol{\pi}=\mathbf{R}-\mathbf{T C}
$$

Dimana:

$\pi=$ Pendapatan

$\mathrm{R}=$ Revenue (Penerimaan)

$\mathrm{TC}=$ Total Cost (Biaya Total)

Kelayakan usaha penangkaran benih kelapa dihitung dengan menggunakan persamaan menurut Suratiyah (2006) sebagai berikut:

$$
\mathrm{R} / \mathrm{C}=\frac{\text { Penerimaan total }}{\text { Biaya total }}
$$

Dengan ketentuan sebagai berikut:

- Apabila R/C > 1, maka usahanya menguntungkan.

- Apabila R/C = 1, maka usahanya tidak rugi dan juga tidak untung.

- Apabila R/C < 1, bahwa usaha tersebut merugikan dan tidak layak. 


\section{HASIL DAN PEMBAHASAN}

\section{Identitas Responden}

Responden berumur 48 tahun sehingga termasuk dalam usia produktif. Menurut Wirosuharjo (2004), penduduk usia produktif adalah penduduk yang berusia antara 15 sampai 64 tahun.

Tingkat pendidikan perannya cukup tinggi terhadap seseorang dalam melakukan kegiatan usaha, karena tingkat pendidikan dapat mempengaruhi seseorang dalam menerima dan melaksanakan hal-hal yang baru. Tingkat pendidikan formal yang dicapai responden adalah D3.

Pengalaman usaha merupakan faktor yang sangat menentukan keberhasilan dalam usahanya, semakin lama pengalaman usaha maka akan semakin terampil dalam melakukan usaha penangkaran benih kelapa. Pengalaman responden dalam melakukan usaha penangkaran benih kelapa yaitu 5 tahun. Melihat pengalaman tersebut dapat dikatakan bahwa responden sudah cukup lama dalam menjalankan usahanya. Pengalaman usaha yang cukup lama sangat bermanfaat bagi responden untuk menjalankan usaha penangkaran benih kelapa dengan baik dan dengan produksi yang tinggi.

Anggota keluarga yang menjadi tanggungan responden sebanyak dua orang, yaitu istri dan satu orang anak. Adanya tanggungan keluarga tentunya akan menjadi motivasi bagi responden untuk dapat meningkatkan usahanya agar kebutuhan keluarga dapat terpenuhi.

\section{Analisis Biaya}

Biaya yang dikeluarkan responden dalam berusaha penangkaran benih kelapa di Kabupaten Pangandaran meliputi biaya tetap dan biaya variabel. Biaya tetap yang dikeluarkan responden meliputi pajak lahan, penyusutan alat, dan bunga modal tetap. Sedangkan biaya variabel yang dikeluarkan responden dalam berusaha penangkaran benih kelapa di Kabupaten Pangandaran meliputi biaya pembelian bibit (biji), pupuk organik kompos, urea, pestisida dan pembayaran tenaga kerja. Untuk lebih jelasnya mengenai biaya total sekali produksi dalam satu kali musim tanam dapat dilihat pada Tabel 1. 
Tabel 1. Biaya Total Usaha Penangkaran Benih Kelapa di Kabupaten Pangandaran

\begin{tabular}{clcc} 
No & \multicolumn{1}{c}{ Komponen Biaya } & Biaya $(\mathbf{R p})$ & Presentase $(\boldsymbol{\%})$ \\
\hline $1 . \quad$ Biaya Tetap & & \\
& (1) Pajak lahan & 125.000 & 0,11 \\
& (2) Penyusutan alat & 1.438 .000 & 1,28 \\
& a. Cangkul & 200.000 & 0,18 \\
& b. Golok & 600.000 & 0,53 \\
& c. Hand Sprayer & 450.000 & 0,40 \\
d. Ember & 50.000 & 0,04 \\
$\quad$ e. Selang & 138.000 & 0,12 \\
(3) Bunga modal & 109.410 & 0,10 \\
$\quad$ Jumlah Biaya Tetap & $\mathbf{1 . 6 7 2 . 4 1 0}$ & $\mathbf{1 , 4 9}$ \\
Biaya Variabel & & \\
(1) Benih & 75.000 .000 & 66,66 \\
(2) Pupuk Kompos & 300.000 & 0,27 \\
(3) Urea & 270.000 & 0,24 \\
(4) Pestisida & 1.025 .000 & 0,91 \\
(5) Tenaga Kerja & 27.000 .000 & 23,99 \\
(6) Bunga Modal & 7.251 .650 & 6,44 \\
$\quad$ Jumlah Biaya Variabel & $\mathbf{1 1 0 . 8 4 6 . 6 5 0}$ & $\mathbf{9 8 , 5 1}$ \\
\hline
\end{tabular}

Analisis Penerimaan dan Pendapatan Usaha Penangkaran Benih Kelapa di Kabupaten Pangandaran

Penerimaan adalah hasil produksi dikalikan dengan harga jual. Produksi yang dihasilkan sebanyak 25.000 benih dengan harga jual benih kelapa Rp 8.000 per benih.

Pendapatan merupakan selisih antara penerimaan dengan biaya total. Penerimaan usaha merupakan perkalian antara produk yang dihasilkan dengan harga jual produk. Penerimaan usaha penangkaran benih kelapa sebesar $\mathrm{Rp}$ 200.000.000 dan biaya total sebesar Rp 112.519.060, sehingga pendapatan sebesar
Rp 87.480.940.

\section{R/C Usaha Penangkaran Benih Kelapa di Kabupaten Pangandaran}

Suratiyah (2006) menyatakan bahwa semakin tinggi $\mathrm{R} / \mathrm{C}$ maka semakin layak dan menguntungkan untuk diusahakan. $\mathrm{R} / \mathrm{C}$ usaha penangkaran benih kelapa sebesar 1,78 maka usaha penangkaran benih kelapa tersebut layak untuk diusahakan. Nilai R/C sebesar 1,78 menunjukkan bahwa dari setiap Rp 1 biaya yang dikeluarkan akan memperoleh penerimaan sebesar $\mathrm{Rp}$ 1,78 rupiah dan pendapatan sebesar $\mathrm{Rp} 0,78$ rupiah.. 


\section{KESIMPULAN DAN SARAN}

\section{Kesimpulan}

Berdasarkan hasil penelitian dan pembahasan, maka dapat ditarik kesimpulan sebagai berikut:

1. Besarnya biaya pada usaha penangkaran benih kelapa di Kabupaten Pangandaran sebesar Rp 112.519.060, penerimaan sebesar $\mathrm{Rp}$ 200.000.000, dan Rp 87.480.940.

2. $\mathrm{R} / \mathrm{C}$ usaha penangkaran benih kelapa di Kabupaten Pangandaran sebesar 1,78. Artinya bahwa setiap Rp 1 biaya yang dikeluarkan petani akan memperoleh penerimaan sebesar Rp 1,78 rupiah dan pendapatan sebesar Rp 0,78 rupiah.

\section{Saran}

Berdasarkan kesimpulan maka disarankan kepada responden agar mempertahankan usahanya, karena usaha penangkaran benih kelapa layak untuk dilaksanakan.

\section{DAFTAR PUSTAKA}

Allorerung, D., dan Z. Mahmud. 2002. Dukungan Kebijakan Iptek Dalam Pemberdayaan Komoditas Kelapa. Prosiding Konferensi Nasional Kelapa V. Tembilahan.

Jumiati, Darwanto, Hartono, dan Masyhuri. 2013. Analisis Saluran Pemasaran dan Marjin Pemasaran Kelapa Dalam Di Daerah Perbatasan KaTimur. Jurnal Agrifor Volume 12 No. 1.

Jumingan. 2009. Analisis Laporan Keuangan. Jakarta: Bumi Aksara.

Soekartawi. 2002. Ilmu Usahatani. Jakarta: UI Press.

Suratiyah, 2006. Ilmu Usahatani. Jakarta: Penebar Swadaya.

Sugiyono, 2007. Metode Penelitian Bisnis. Alfabeta. Bandung

Yurianto. 2008. Analisis Saluran Pemasaran Kacang Tanah. 2016. 